\title{
Deficiência de fósforo em caprinos no semiárido de Pernambuco ${ }^{1}$
}

\author{
Fernanda P.S. Barbosa ${ }^{2}$, Valdir M. Almeida ${ }^{2}$, Raquel F. Albuquerque ${ }^{2}$, \\ Brena P. Rocha ${ }^{2}$, Pierre C. Soares ${ }^{3}$, Givaldo B. Silva Filho ${ }^{4}$, Hisadora A. Chaves ${ }^{4}$ \\ e Fábio S. Mendonça**
}

\begin{abstract}
Barbosa F.P.S., Almeida V.M., Albuquerque R.F., Rocha B.P., Soares P.C., Silva Filho G.B., Chaves H.A. \& Mendonça F.S. 2018. [Phosphorus deficiency in goats in the semiarid region of Pernambuco, Brazil.] Deficiência de fósforo em caprinos no semiárido de Pernambuco. Pesquisa Veterinária Brasileira 38(6):1117-1124. Departamento de Morfologia e Fisiologia Animal, Universidade Federal Rural de Pernambuco, Rua Dom Manoel de Medeiros, Dois Irmãos, Recife, PE 52171-900, Brazil. E-mail: fabio.mendonca@pq.cnpq.br

The aim of this study was to evaluate the clinical and pathological aspects of phosphorus deficiency in goats in the semiarid region of Pernambuco. For this, technical visits were carried out at different properties in the Sertão do Moxotó region during the dry season period. Clinical examinations, serum analysis and rib biopsies were carried out to determine macromineral contents. Serum concentrations of total and ionized $\mathrm{Ca}$, serum and bone $\mathrm{P}$, $\mathrm{Mg}$, Ca:P ratio, total protein, albumin, globulin and ashes were determined. Bone biopsies were performed by surgical procedure in the hypochondriac region of the 12th right rib which were fixed in $10 \%$ formalin solution and decalcified for histological analysis. The main clinical signs in phosphorus-deficient goats consisted of dehydration, poor corporal score, ruminal hypomotility, alopecia, opaque, brittle and bristly hair and osteophagy. The averages of bone ashes and phosphorus content in bones were below the reference values and the correlation between these two variables was strongly positive $(r=0.91)$. The reduction of the serum phosphorus concentration was accompanied by the reduction of the percentage of this mineral in the ashes. This result is conclusive for the diagnosis of phosphorus deficiency. In the microscopic examination of ribs bony fragments there was a clear increase in osteoclastic activity with areas of bone resorption and a greater amount of osteoid tissue and collagen fibers in the bone matrix. It is concluded that phosphorus deficiency is a frequent disease in goats in the semiarid region of Pernambuco, Brazil and and the supplementation of this mineral is necessary in the studied region.
\end{abstract}

INDEX TERMS: Phosphorus deficiency, goats, Brazilian semiarid region, osteophagy, hypophosphorosis, macrominerals, mineral nutrition, ruminants, clinics.

RESUMO.- 0 objetivo deste estudo foi avaliar os aspectos clínicos e patológicos da deficiência de fósforo em caprinos no semiárido de Pernambuco. Para isso, visitas técnicas

\footnotetext{
${ }^{1}$ Recebido em 3 de Junho de 2017.

Aceito para publicação em 19 de Junho de 2017.

${ }^{2}$ Programa de Pós-Graduação em Medicina Veterinária, Universidade Federal Rural de Pernambuco (UFRPE), Rua Dom Manoel de Medeiros, Dois Irmãos, Recife, PE 52171-900, Brasil.

${ }^{3}$ Departamento de Medicina Veterinária, Universidade Federal Rural de Pernambuco (UFRPE), Rua Dom Manoel de Medeiros, Dois Irmãos, Recife, PE 52171-900.

${ }^{4}$ Laboratório de Diagnóstico Animal, Departamento de Morfologia e Fisiologia Animal, Universidade Federal Rural de Pernambuco (UFRPE), Recife, PE 52171-900. *Autor para correspondência: fabio.mendonca@pq.cnpq.br
}

foram realizadas em diferentes propriedades na microrregião do Sertão do Moxotó durante o período da estação seca. Realizaram-se exames clínicos, determinação da atividade sérica de cálcio total e ionizado, fosforo sérico, magnésio, razão Ca:P, proteína total, albumina, globulina e o percentual de cinzas ósseas. Biopsias ósseas da região hipocondríaca da 12 costela direita foram fixadas em solução de formalina a $10 \%$ e descalcificadas para análises histológicas. Os principais sinais clínicos observados nos caprinos com deficiência de fósforo foram aumento da fragilidade óssea além de desidratação, magreza, hipomotilidade ruminal, alopecia, pelos opacos, quebradiços e eriçados e osteofagia. As médias dos valores das cinzas ósseas e do teor de fósforo nos ossos estavam abaixo dos valores de referência e a correlação entre essas duas variáveis foi fortemente positiva $(\mathrm{r}=0,91)$; a redução da 
concentração do fósforo sérico foi acompanhada da redução da porcentagem desse mineral nas cinzas. Esse resultado é conclusivo para o diagnóstico de deficiência de fósforo. No exame microscópico dos fragmentos ósseos das costelas, verificou-se evidente aumento da atividade osteoclástica com áreas de reabsorção óssea e maior quantidade de tecido osteóide e de fibras colágenas na matriz óssea. Conclui-se que a deficiência de fósforo é uma doença frequente em caprinos criados em regime semi-extensivo no semiárido de Pernambuco e que a suplementação desse mineral é necessária na região estudada.

TERMOS DE INDEXAÇÃO: Deficiência de fósforo, caprinos, semiárido brasileiro, osteofagia, hipofosforose, macrominerais, nutrição mineral, ruminantes, clínica.

\section{INTRODUÇÃO}

O Estado de Pernambuco detém um rebanho aproximado de 2,43 milhões de caprinos (Brasil 2015) e apesar da caprinocultura ser uma das atividades mais representativas para os produtores rurais, sobretudo nas regiões do agreste e do sertão do Estado, as criações são geralmente praticadas com manejo inadequado, principalmente no que se refere à alimentação e profilaxia de doenças (Sampaio et al. 2009). Pouco se sabe sobre a incidência e prevalência das principais doenças que acometem caprinos, sobretudo aquelas relacionadas a distúrbios metabólicos e nutricionais (Silva Júnior et al. 2015).

A deficiência de fósforo, principalmente em animais criados de forma extensiva, é o distúrbio mineral mais importante para ruminantes, pois extensas áreas de pastagens no Brasil são deficientes em fósforo. Dessa forma os rebanhos consomem dietas que não correspondem às suas necessidades (Riet-Correa et al. 2007, Tokarnia et al. 2010). No semiárido brasileiro, a caprinocultura caracteriza-se principalmente pela adoção de práticas de criação de animais em regime extensivo na caatinga. Nessa região, os valores de fósforo encontrados nas pastagens são considerados abaixo do recomendado para ruminantes (Silva et al. 2011) e a suplementação mineral dos rebanhos não é uma prática comumente empregada (Drumond et al. 2000).

A deficiência de fósforo pode ocorrer sob diversos graus, desde deficiências severas, com lesões mais características, até deficiências leves, com sinais clínicos inespecíficos. Os principais problemas estão relacionados à inibição do crescimento, perda de peso e redução e/ou perda de apetite, redução da produção de carne e leite, queda na fertilidade (Ternouth \& Sevilla 1990, McDowell 1992, Underwood \& Suttle 1999) e diminuição de resistência contra doenças, especialmente verminoses (Tokarnia et al. 2010). Ruminantes deficientes em fósforo podem apresentar comportamento de osteofagia (levando à engasgos ou botulismo epizoótico) e alterações do esqueleto, tais como fraturas e deformidades ósseas. A hipofosfatemia é ainda causa de raquitismo em animais jovens e osteomalácia em adultos (Meschy 2000, Riet-Correa et al. 2007, Tokarnia et al. 2010, Duarte et al. 2011).

Apesar dos esforços de pesquisadores em estudar exigências nutricionais de caprinos no Brasil, os estudos têm sido conduzidos com animais em regime de confinamento e geneticamente diferentes dos animais da realidade da região semiárida brasileira. Dados sobre as deficiências minerais em ruminantes correspondem principalmente às deficiências em bovinos e bubalinos. A exigência nutricional de caprinos em pastejo não tem sido estudada e a deficiência de fósforo não é comumente relatada nessa espécie, pois se acredita que os caprinos são menos sensíveis a esta deficiência em virtude de seus hábitos alimentares relacionados ao consumo de brotos dos arbustos (Pugh 2005, Tokarnia et al. 2010).

O objetivo deste trabalho foi estudar aspectos clínicos e patológicos da deficiência de fósforo em caprinos no semiárido de Pernambuco.

\section{MATERIAL E MÉTODOS}

Visitas técnicas para estudar casos de deficiência de fósforo em caprinos foram realizadas em propriedades na microrregião do Sertão do Moxotó, Estado de Pernambuco, nos Municípios de Arcoverde, Betânia, Custódia, Ibimirim, Inajá, Manari e Sertânia (Fig.1), durante o período da estação seca, que nesta microrregião se estende de dezembro a março. Uma fazenda foi visitada em cada município, e para verificar a presença ou ausência de anormalidades clínicas, $25 \%$ dos caprinos de cada rebanho foi selecionado aleatoriamente e examinados clinicamente de acordo com Smith \& Sherman (2009). Nesses animais também foi realizado o teste para avaliação da fragilidade óssea, utilizando-se, para isso, agulha hipodérmica calibre 40x12, inserida na asa ilíaca. Nos casos em que a agulha penetrava facilmente no tecido ósseo, o teste era considerado positivo (Tokarnia et al. 2010).

Dez caprinos adultos positivos no teste de fragilidade óssea foram selecionados. Em seguida, amostras de sangue foram coletadas por meio de venopunção jugular com uso de tubos a vácuo sem anticoagulante com capacidade para cinco mililitros, para a obtenção posterior de soro, após centrifugação (3.000 rpm por cinco minutos). Concentrações de fósforo, cálcio, magnésio, proteína total e albumina foram realizadas por teste colorimétrico, utilizando-se Kits comerciais em analisador bioquímico semiautomático Labtest ${ }^{\circledR}$. 0 cálcio ionizado foi obtido mediante a utilização de fórmula segundo metodologia empregada pelo fabricante e a razão Ca:P foi obtida dividindo-se o valor do cálcio total pelo valor do fósforo.

Para a realização de biopsias ósseas os caprinos foram sedados com acepromazina a $0,2 \%$ e anestesiados com cetamina a $10 \%$. Posteriormente, foram extraídos cirurgicamente fragmentos ósseos de aproximadamente cinco centímetros da $12^{-a}$ costela na região hipocondríaca direita de acordo como descrito por Little (1972). Esses fragmentos foram utilizados para a verificação do percentual de cinzas, teor de fósforo no tecido ósseo e análise histológica.

Para determinação da porcentagem de cinzas, as amostras de tecido ósseo foram colocadas para secar por 12 horas a $105^{\circ} \mathrm{C} \mathrm{em}$ estufa, para o registro do peso seco. Em seguida, foram calcinados em mufla a $600^{\circ} \mathrm{C}$ durante 12 horas, para obtenção do peso seco desengordurado. As amostras calcinadas foram trituradas em gral e pistilo para obtenção das cinzas, que foram pesadas e armazenadas em tubos de vidros estéreis (Fick et al. 1979). 0 percentual de cinzas ósseas foi determinado de acordo com as recomendações de Mendes (1977). Todos os resultados foram expressos em porcentagem, tendo como base a matéria seca livre de gordura. 0 teor de fósforo orgânico nos ossos foi analisado após a digestão das cinzas com ácido sulfúrico e peróxido de hidrogênio de acordo com a metodologia descrita por Thomas et al. (1967). Posteriormente, o teor de fósforo orgânico foi determinado por meio de espectrofotometria com leitura da intensidade da cor do complexo fosfomolíbdico produzido pela redução do molibdato com ácido ascórbico (Murphy \& Riley 1962).

Para análise histológica, fragmentos de costelas foram fixados em solução de formalina a $10 \%$ e descalcificados em solução de citrato de sódio e ácido fórmico por 96 horas (Tolosa et al. 2003). 


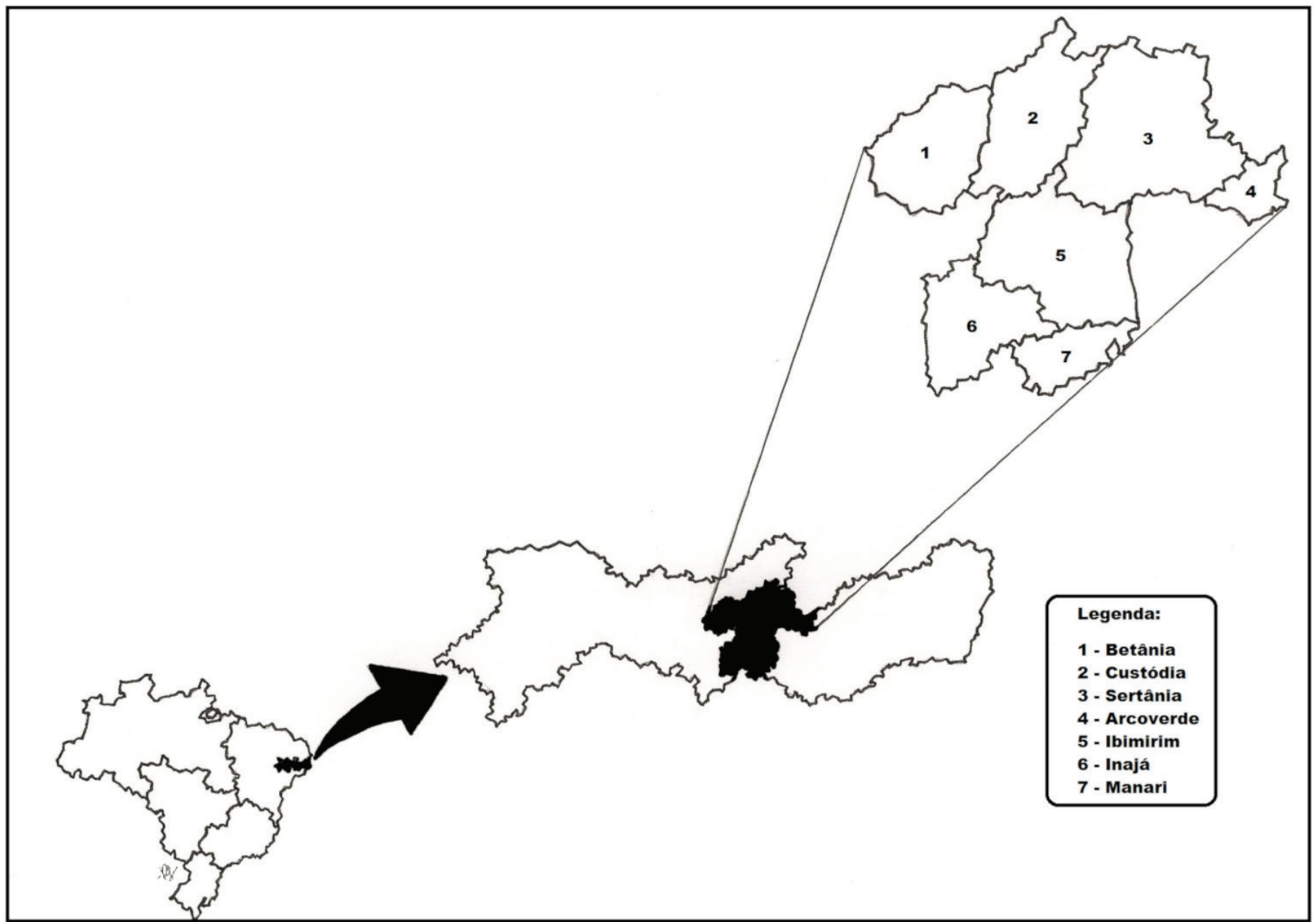

Fig.1. Mapa geográfico do Brasil destacando o Estado de Pernambuco, o Sertão do Moxotó e em maior aumento os Municípios estudados.

As amostras foram processadas de acordo com as técnicas histológicas de rotina, corados por hematoxilina e eosina (HE), pela técnica histoquímica de tricrômico de Gômori e em seguida examinados em microscópio de luz.

A análise estatística foi realizada através do processamento dos dados considerando-se medidas de tendência central e dispersão de frequências. Efetuou-se a análise de associação entre pares de variáveis com a determinação do coeficiente de correlação de Pearson. A significância obtida na correlação foi feita segundo Little \& Hills (1978). Os dados foram analisados por meio do recurso computacional Microsoft Excel 2010.

\section{RESULTADOS}

Em todas as propriedades visitadas na área de abrangência desse estudo, o manejo adotado era o semi-extensivo em que os caprinos eram soltos no período da manhã, para pastar nas áreas de caatinga e eram recolhidos no fim da tarde para os apriscos onde recebiam, quando disponível, quirera de milho ou palma forrageira (Opuntia ficus-indica Mill. ou Nopalea cochenillifera (L.) Salm-Dyck). Nessas propriedades os caprinos não recebiam suplementação mineral ou ração comercial. Nos caprinos positivos no teste de fragilidade óssea, os principais sinais clínicos observados consistiram em desidratação, magreza, hipomotilidade ruminal, alopecia, pelos opacos, quebradiços e eriçados e osteofagia (Fig.2).

A concentração sérica de Ca total foi de 2,46mmol/L, do Ca ionizado foi de 1,38mmol/L, do P sérico foi de 1,7mmol/L e da relação Ca:P foi de 1,41mmol/L. A concentração média de Mg foi de 0,4mmol/L. A concentração sérica de proteína total foi de $65,3 \mathrm{~g} / \mathrm{L}$, enquanto que a albumina foi de $29,75 \mathrm{~g} / \mathrm{L} \mathrm{e}$ globulina de $53,57 \mathrm{~g} / \mathrm{L}$. 0 percentual de cinzas das costelas foi de 55,3\% e a concentração de P ósseo foi de 9,1\%. (Quadro 1).

Foram identificadas correlações altamente positivas entre 0 percentual de cinzas dos ossos das costelas coma concentração sérica de fósforo $(r=0,90 ; p<0,0001)$, com a concentração sérica de cálcio total ( $\mathrm{r}=0,67 ; \mathrm{p}<0,0001)$, porém negativa com a razão Ca:P sérica ( $r=-0,70 ; p<0,0001)$. Correlação altamente negativa foi observada entre a concentração sérica de fósforo com a razão $\mathrm{Ca}: \mathrm{P}(\mathrm{r}=-0,89 ; \mathrm{p}<0,0001)$. Tais equações de regressão das correlações e seus respectivos coeficientes de correlação e níveis de significância encontram-se expressos na Figura 3.

No exame microscópico dos fragmentos ósseos das costelas, foram registradas alterações ósseas com diferentes níveis de intensidade em todos os fragmentos analisados. Essas alterações variaram de incipientes à moderadas. Verificou-se aumento da atividade osteoclástica com áreas de reabsorção óssea e 

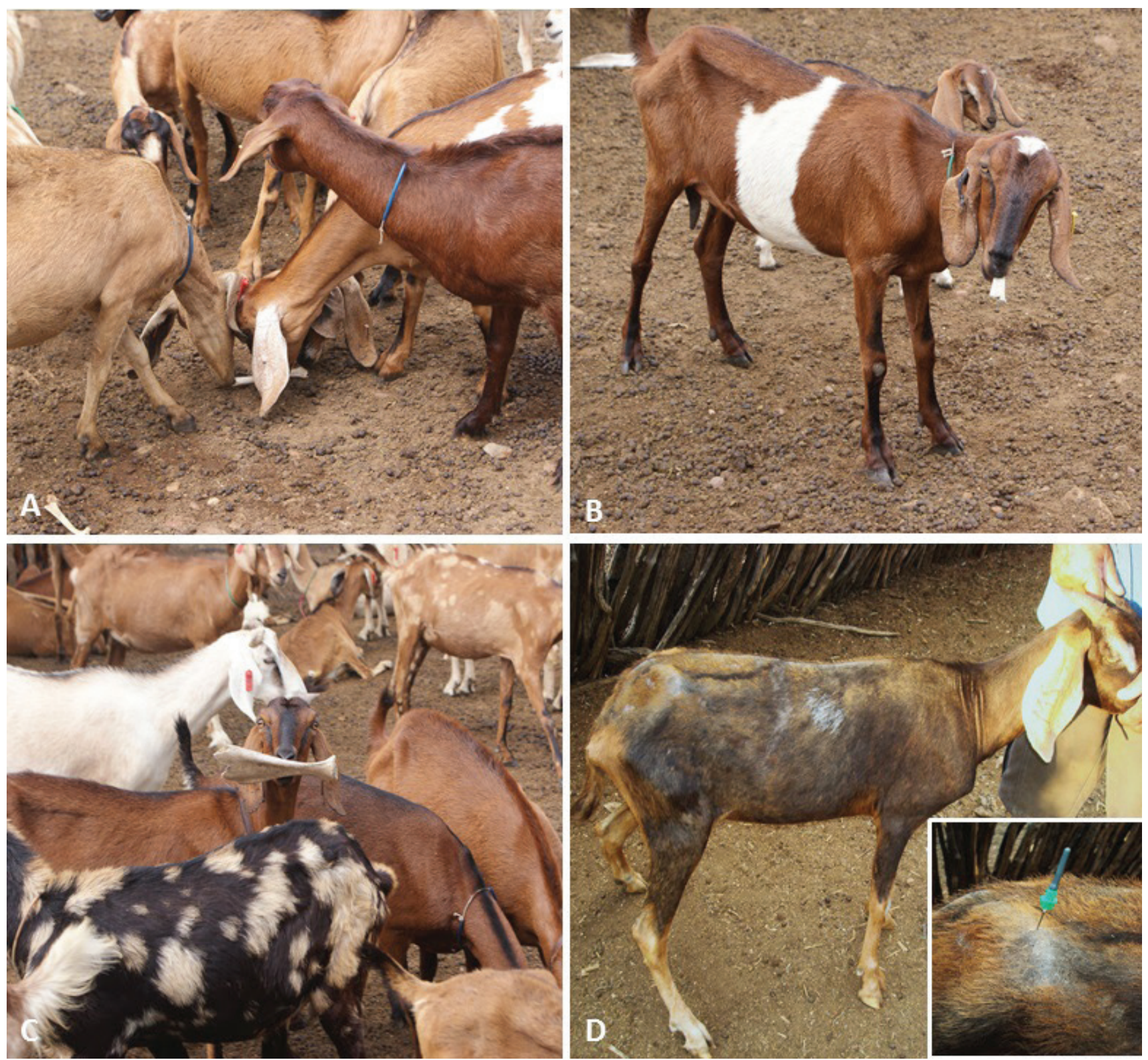

Fig.2. Deficiência de fósforo em caprinos. (A-C) Caprinos de diferentes rebanhos apresentando comportamento de osteofagia. (D) Caprino com alopecia e positividade para o teste de fragilidade óssea da asa ilíaca (detalhe).

Quadro 1. Medidas de tendência central, valores de referência de minerais no soro sanguíneo e ossos dos caprinos com deficiência de fósforo no estado de Pernambuco

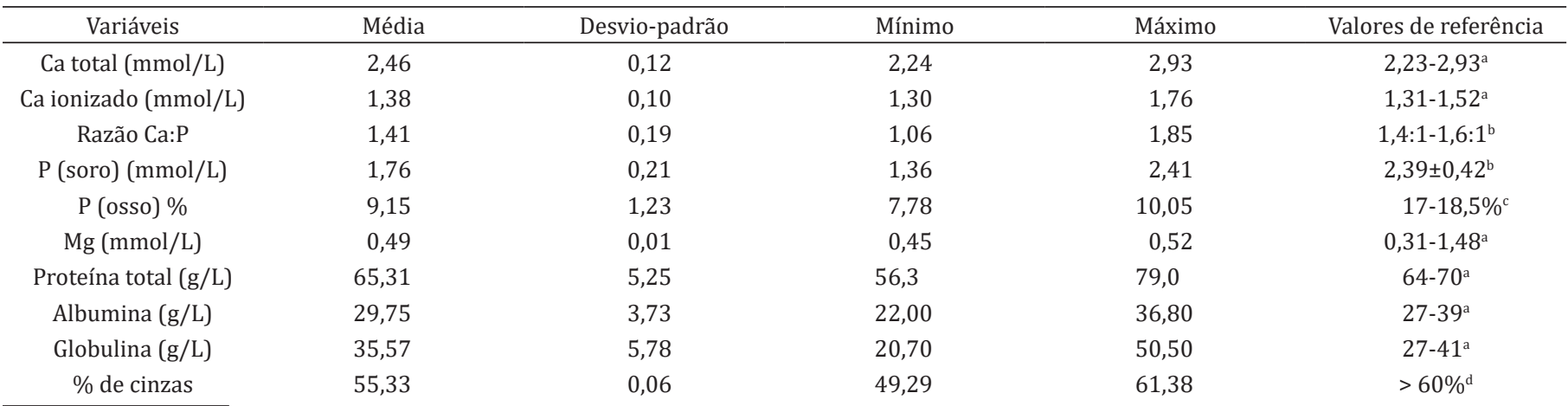

$\bar{a}$ Kaneko et al. (2008), ${ }^{\text {b }}$ Barioni et al. (2001), ${ }^{\mathrm{c}}$ McDowell (1992), ${ }^{\mathrm{d}}$ Little (1972). 

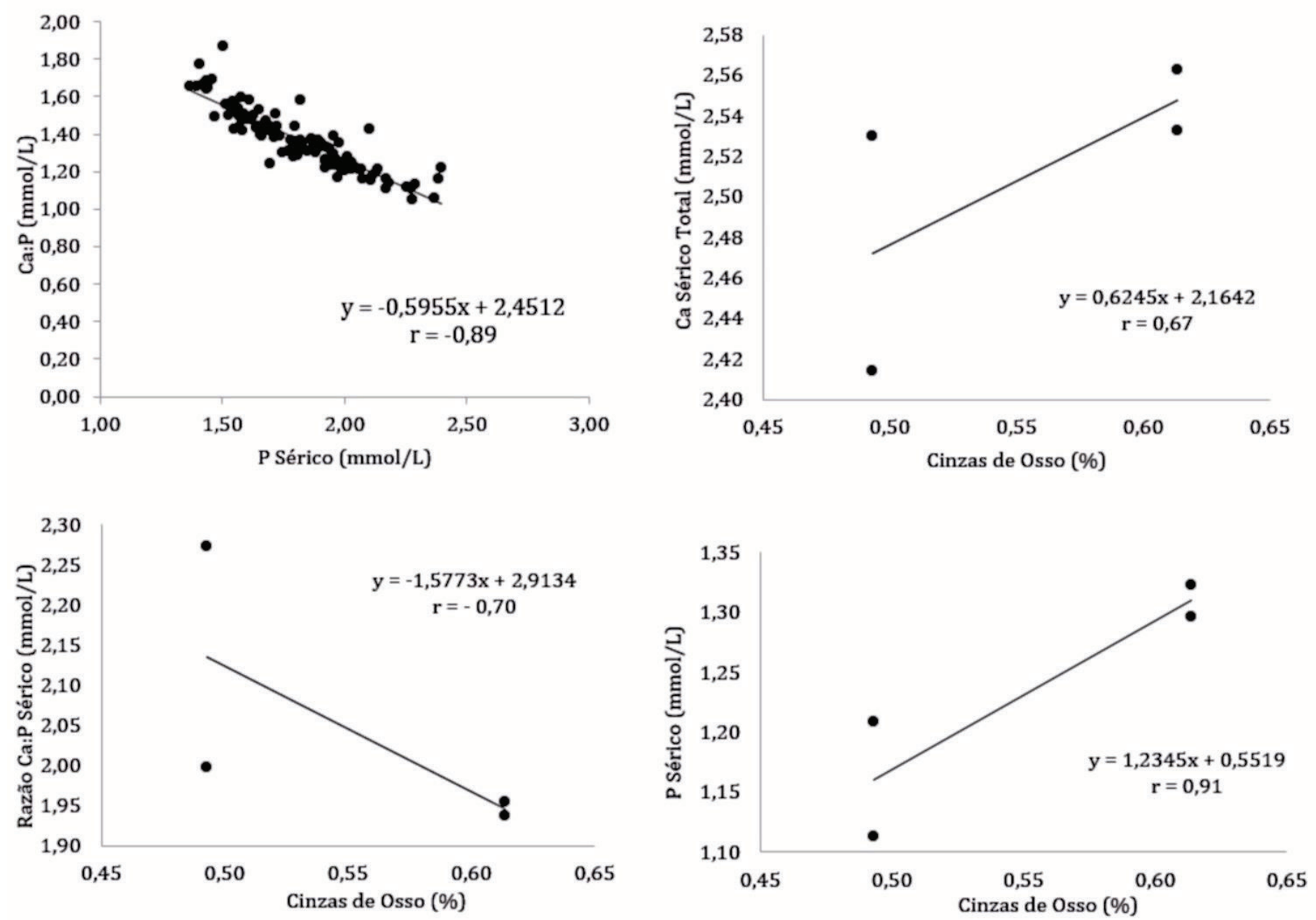

Fig.3. Representação gráfica com respectivas equações de regressão e coeficientes de correlação de Pearson da relação entre variáveis (Cinzas de ossos, P sérico, Ca sérico e razão Ca:P) analisadas em caprinos com deficiência de fósforo.

maior quantidade de tecido osteóide; nos fragmentos corados pelo tricrômico de Gômori, havia maior proliferação de fibras colágenas na matriz óssea. Tanto os ossos corticais quanto os ossos trabeculares, quando corados pela hematoxilina-eosina, apresentavam sistemas de Havers preenchidos por osteóide desmineralizado (fracamente eosinofílico) e significante presença de linhas de reversão. Havia, ainda, aumento da atividade osteoblástica com formação de áreas de tecido ósseo pobremente mineralizado, com padrão irregular (osso imaturo) e redução da quantidade de lacunas/osteócitos (Fig.4).

\section{DISCUSSÃO}

O diagnóstico de deficiência de fósforo nos caprinos dos rebanhos deste estudo foi baseado nos sinais clínicos, nas concentrações de fósforo no soro, ossos e porcentagem de cinzas que se encontravam abaixo dos valores de referência para a espécie (Kaneko et al. 2008).

O quadro clínico patológico mais característico da deficiência de fósforo em bovinos e bubalinos está relacionado ao hábito de roer ossos (Tokarnia et al. 2010). Osteofagia é uma condição pouco relatada em caprinos, porém, no semiárido do Piauí foi associada a um surto de botulismo (Riet-Correa et al. 2012).
Nos caprinos deste estudo, osteofagia foi observada com intensidades variáveis nos rebanhos examinados. Portanto, deve ser também considerada pelos médicos veterinários que trabalham a campo, pois quando presente constitui-se em um sinal relativamente específico para o diagnóstico de hipofosforose nessa espécie, principalmente se estiver associada à presença de sinais clínicos compatíveis com botulismo (Riet-Correa et al. 2007, 2012, Tokarnia et al. 2010). Outro aspecto importante da deficiência severa de fósforo em bovinos e bubalinos adultos são as alterações do esqueleto, tais como desvios ósseos, alterações posturais e fraturas espontâneas (Radostits et al. 2002, Riet-Correa 2004, Pugh 2005, Smith 2006). Essas alterações do esqueleto não foram observadas nos caprinos desse estudo. A alteração óssea mais perceptível foi a positividade nos testes de fragilidade óssea da asa ilíaca.

Em caprinos, outras doenças podem ser a causa de fragilidade óssea, tais como, raquitismo, osteomalácia, osteodistrofia fibrosa nutricional e deficiência de cobre (Smith \& Sherman 2009). 0 raquitismo é uma anormalidade óssea metabólica de animais jovens, ainda em crescimento e atribuída principalmente à deficiência de vitamina $D\left(D_{2}\right.$ - ergocalciferol ou $D_{3}$ - colecalciferol), que resulta em inadequada mineralização das epífises, 

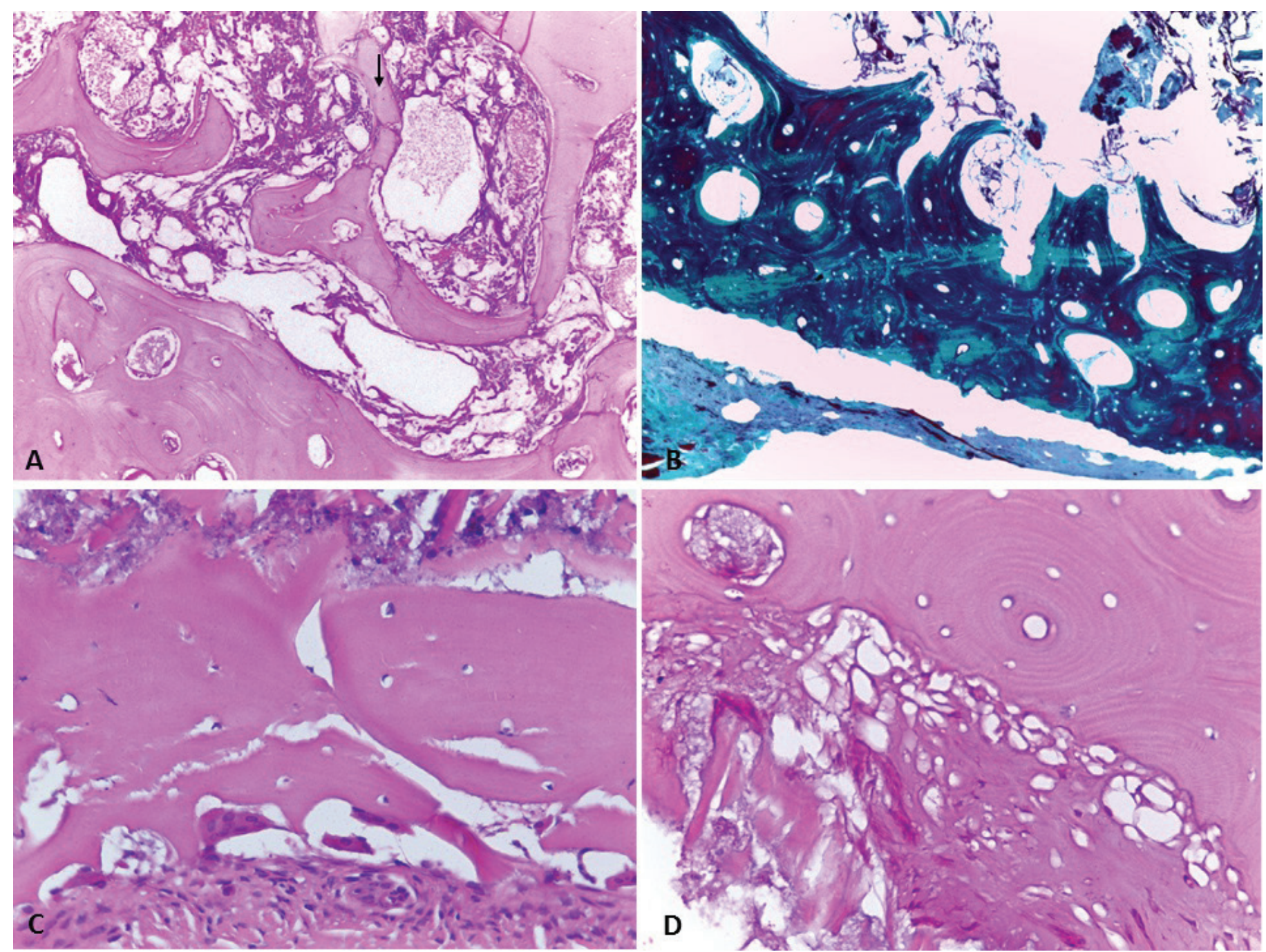

Fig.4. Deficiência de fósforo em caprinos. (A) Cavidades de reabsorção dentro de trabéculas ósseas e sistemas de Havers preenchidos por áreas eosinofílicas pálidas, compatíveis com osteóide não mineralizado. HE, obj.4x. (B) Osso cortical com significante desmineralização dos sistemas de Havers, evidenciada pela severa qauntidade de fibras colágenas. Tricrômico de Gomori, obj.4x. (C) Osso cortical com presença de osteoclastos e lacunas de Howship indicando reabsorção ativa. HE, obj.10x. (D) Desmineralização de osso cortical com ampla margem de tecido osteóide e aumento da atividade osteoclástica. HE, obj.10x.

com aumento do volume das articulações e crescimento ósseo anormal. Caprinos adultos podem desenvolver osteomalácia/osteoporose. Nesses casos, os sinais clínicos podem ser similares aos descritos nesse estudo e podem incluir fraqueza, dificuldade de locomoção e maior tempo em decúbito (Smith \& Sherman 2009, Rosa et al. 2013). Porém, na osteomalácia se observa deficiência de vitamina $D$, raramente observada em ruminantes criados em regime extensivo (Malafaia et al. 2014), ou deficiência de cálcio e fósforo (Braun et al. 2009, Rosa et al. 2013).

A osteodistrofia fibrosa é uma desordem metabólica caracterizada por reabsorção óssea extensa, proliferação de tecidos conjuntivos fibrosos e mineralização insuficiente dos tecidos ósseos. A patogênese envolve o aumento persistente dos níveis de paratormônio no plasma (Thompson 2007) e, em caprinos, está geralmente associada ao hiperparatireoidismo secundário nutricional, em que os níveis séricos de cálcio estão diminuídos, geralmente devido ao consumo de dietas hipocalcêmicas e/ou hiperfosfatêmicas (Bandarra et al. 2011). Na deficiência de cobre em caprinos, também pode haver osteopenia com ou sem ocorrência de fraturas espontâneas. Nesses casos, o mecanismo das lesões ósseas é desconhecido, mas provavelmente tem relação com a lizil oxidase, uma metaloenzima dependente de cobre que é fundamental para o metabolismo ósseo (Stover 2006, Buck et al. 2012).

Em relação às concentrações de cálcio total e cálcio ionizado nos caprinos desse estudo, foi observado que os valores se encontravam de acordo com os parâmetros normais para a espécie caprina (Kaneko et al. 2008). A determinação da concentração do cálcio ionizado é importante porque esse parâmetro fornece resultados mais fidedignos quando comparado ao cálcio total, por representar a forma do cálcio biologicamente ativa (Kaneko et al. 2008). Porém, no estudo da relação entre a concentração sérica de fósforo e a razão Ca:P observou-se um resultado fortemente negativo $(r=-0,89)$; isto é, enquanto as concentrações de cálcio se mantiveram 
elevadas, as de fósforo se mantiveram baixas. Esses dados confirmam, portanto, que os caprinos desse estudo não apresentavam osteodistrofia fibrosa, pois não apresentavam deficiência de cálcio.

Nesse estudo, as médias dos valores das cinzas ósseas e do teor de fósforo nos ossos estavam abaixo do valor de referência e a correlação entre essas duas variáveis foi fortemente positiva $(\mathrm{r}=0,91)$, ou seja, a redução da concentração do fósforo sérico foi acompanhada da redução da porcentagem desse mineral nas cinzas. Esse resultado é conclusivo para o diagnóstico de deficiência de fósforo. Porém, em situações de campo, a determinação de concentrações séricas, dada sua rapidez de realização e economia, podem ser realizadas para se ter uma visão mais panorâmica do perfil da deficiência em rebanhos (Duarte et al. 2011). Verificou-se, também, que quanto menor o percentual de cinzas no osso, menor foi a concentração óssea de cálcio total $(\mathrm{r}=0,67)$ e maior a ração Ca:P $(\mathrm{r}=0,70)$. Deste modo, a observação de caprinos com osteofagia e positividade nos testes de fragilidade óssea da asa ilíaca, associados aos resultados laboratoriais demonstram haver indicadores fortemente relacionados com hipofosforose.

Embora os resultados da proteína total, albumina e globulina estivessem dentro do intervalo de normalidade, destaca-se que a proteína total e a albumina tiveram resultados muito próximos ao limite inferior da referência para a espécie. Esta dinâmica geralmente é encontrada quando existe um agravamento da condição clínica, em que os animais demonstram perda progressiva de peso, modificação do estado sensorial e motor, com sinais bem característicos de quadros de hipofosforose (Tokarnia et al. 2010). Em relação às concentrações de magnésio, foi observado que os valores se mantiveram normais e que não houve interferência com a concentração sérica de cálcio, demonstrada pela fraca correlação negativa entre essas varáveis $(r=-0,13)$. Deve-se lembrar de que a determinação da concentração de magnésio é importante nesse tipo de estudo porque existem casos em que a hipermagnesemia pode ocasionar hipocalcemia (Kaneko et al. 2008).

As lesões histológicas observadas nos caprinos deste estudo são condizentes com as descritas previamente na literatura em ruminantes com deficiência de fósforo (Tokarnia et al. 2010, Silva et al. 2011) e se caracterizaram principalmente pela presença tecido osteóide desmineralizado, maior atividade osteoclástica, substituição do tecido ósseo por osteóide ou tecido conjuntivo denso modelado em áreas de osso compacto. A presença de linhas de reversão indica uma significante reabsorção óssea. Essas lesões são condizentes com falhas durante os processos de mineralização e depósito de osteóide durante o processo remodelamento ósseo e podem ser frequentemente irregulares e acompanhadas de rupturas do osso trabecular (Craig et al. 2015).

Está bem estabelecida a importância que as deficiências e a suplementação de minerais exercem na sanidade, produtividade e na economia da atividade pecuária brasileira. Apesar disso, não se pode perder de vista o impacto que a suplementação mineral representa nos custos operacionais de uma fazenda. Dessa maneira, alguns pontos críticos devem ser observados antes de iniciar uma suplementação, como por exemplo: não suplementar minerais se não há sinais diretos ou indiretos de deficiência mineral; a suplementação mineral deve ser ajustada ao nível de produção; pouco adianta suplementar minerais sem a prévia adequação protéica-energética da dieta e sem uma adequada disponibilidade de volumoso; as necessidades da suplementação mineral variam com a região, época do ano e com o manejo alimentar do rebanho; a formulação mineral deve ser feita caso a caso, isto é, fazenda a fazenda (Peixoto et al. 2005, Malafaia et al. 2014).

\section{CONCLUSÃO}

A deficiência de fósforo é uma doença frequente em caprinos criados em regime semiextensivo no Sertão do Moxotó, Estado de Pernambuco, e a suplementação desse mineral é necessária na região estudada.

\section{REFERÊNCIAS}

Bandarra P.M., Pavarini S.P., Santos A.S., Antoniassi N.A.B., Cruz C.E.F. \& Driemeier D. 2011. Nutritional fibrous osteodystrophy in goats. Pesq. Vet. Bras. 31(10):875-878. http://dx.doi.org/10.1590/S0100-736X2011001000007.

Barioni G., Fonteque J.H., Paes P.R.O., Takahira R.K., Kohayagawa A., Lopes R.S., Lopes S.T.A. \& Crocci A.J. 2001. Valores séricos de cálcio, fósforo, sódio, potássio e proteínas totais em caprinos fêmeas da raça Parda Alpina. Ciência Rural 31(3):435-438. http://dx.doi.org/10.1590/S010384782001000300011.

Brasil 2015. Produção da Pecuária Municipal. Ministério do Desenvolvimento Agrário, Secretária de Desenvolvimento Territorial, Brasília, p.23-24.

Braun U., Ohlerth S., Liesegang A., Forster E., Gorber U., Tschuor A., Bearth G., Muntwyler J., Wiederkehr D. \& Ossent P. 2009. Osteoporosis in goats associated with phosphorus and calcium deficiency. Vet. Rec. 164(7):211213. http://dx.doi.org/10.1136/vr.164.7.211. PMid:19218593.

Buck B.C., Ulrich R., Taube V., Jacobsen B. \& Ganter M. 2012. Osteopenia as a result of copper deficiency in a dwarf Thuringian Forest goat. Tierarztl Prax Ausg G Grosstiere Nutztiere 40(1):45-52. PMid:22331291.

Craig L.E., Dittmer K.E. \& Thompsom K.G. 2016. Bones and joints, p.60-82. In: Maxie M.G. (Ed), Kennedy \& Palmer's Pathology of Domestic Animals. Vol.1. 6th ed. Elsevier, Philadelphia.

Drumond M.A., Kill L.H.P., Lima P.C.F., Oliveira M.C., Oliveira V.R., Albuquerque S.G., Nascimento C.E.S. \& Cavalcanti J. 2000. Estratégias para o uso sustentável da biodiversidade da caatinga. Seminário "Biodiversidade da Caatinga", Petrolina, PE, p.1-3.

Duarte A.L.L., Pires M.L.S., Barbosa R.R., Dias R.V.C. \& Soto-Blanco B. 2011 Avaliação da deficiência de fósforo em ruminantes por meio de bioquímica sérica. Acta Vet. Bras. 5(4):380-384.

Fick K.R., McDowell L.R., Miles P.H., Wilkinson N.S., Funk J.D. \& Conrad J.H. 1979. Methods of Mineral Analysis for Plants and Animal Tissues. 3rd ed. University of Florida, Gainesville. p.11-25.

Kaneko J.J., Harvey J.W. \& Bruss M.L. 2008. Clinical Biochemistry of Domestic Animals. 6th ed. Academic Press, San Diego. p.303-323.

Little D.A. 1972. Bone biopsy in cattle and sheep for studies of phosphorus status. Aust. Vet. J. 48(12):668-670. http://dx.doi.org/10.1111/j.1751-0813.1972. tb09244.x. PMid:4658447.

Little T.M. \& Hills F.J. 1978. Agricultural Experimentation: Design and Analysis. John Wiley \& Sons, New York. p.112-127.

Malafaia P., Costa R.M., Brito M.F., Peixoto P.V., Barbosa J.D., Tokarnia C.H. \& Döbereiner J. 2014. Equívocos arraigados no meio pecuário sobre deficiências e suplementação minerais em bovinos no Brasil. Pesq. Vet. Bras. 34(3):244-249. http://dx.doi.org/10.1590/S0100-736X2014000300008.

McDowell L.R. 1992. Minerals in Animal and Human Nutrition. Academic Press, San Diego. p.33-100. 
Mendes M.O. 1977. Mineral status of beef cattle in the northern part of Mato Grosso, Brazil, as indicated by age, season, and sampling technique. Dissertation, University of Florida, Gainesville. 236p.

Meschy F. 2000. Recent progress in the assessment of mineral requirements of goats. Livestock Prod. Sci. 64(1):9-14. http://dx.doi.org/10.1016/ S0301-6226(00)00171-8.

Murphy J. \& Riley J.P.A.A. 1962. Modified simple solution method for the determination of phosphate in natural waters. Anal. Chim. Acta 27:31-36. http://dx.doi.org/10.1016/S0003-2670(00)88444-5.

Peixoto P.V., Malafaia P., Barbosa J.D. \& Tokarnia C.H. 2005. Princípios de suplementação mineral em ruminantes. Pesq. Vet. Bras. 25(3):195-200. http://dx.doi.org/10.1590/S0100-736X2005000300011.

Pugh D.G. 2005. Clínica de Ovinos e Caprinos. Roca, São Paulo, p.145-208.

Radostits O.M., Blood D.C. \& Hinchcliff K.W. 2002. Clínica Veterinária: um Tratado de Doenças dos Bovinos, Ovinos, Suínos, Caprinos e Equinos. 9a ed. Guanabara Koogan, Rio de Janeiro. p.1015-1070.

Riet-Correa F. 2004. Suplementação mineral em pequenos ruminantes no semiárido. Ciênc. Vet. Trop. 7:113-130.

Riet-Correa F., Schild A.L., Lemos R.A. \& Borges J.R.J. 2007. Doenças de Ruminantes e Equídeos. Vol.2. 3aㅗ ed. Pallotti, Santa Maria.

Riet-Correa F., Medeiros R.M.T., Tokarnia C.H., Carvalho C.S., Franklin F.L.A.A., Dias A.C.S., Ferreira R.M.M. \& Silva S.M.M.S. 2012. Botulism by Clostridium botulinum type C in goats associated with osteophagia. Small Rum. Res. 106(2/3):201-205. http://dx.doi.org/10.1016/j.smallrumres.2012.03.010.

Rosa F.B., Galiza G.J.N., Lucena R.B., Silva T.M., Caprioli R.A., Barros C.S.L., Fighera R.A. \& Kommers G.D. 2013. Osteoporose em caprinos. Pesq. Vet. Bras 33(4):483-489. http://dx.doi.org/10.1590/S0100-736X2013000400012.

Sampaio B.R., Sampaio Y., Lima R., Aires A. \& Sampaio G. 2009. A Economia da caprinocultura em Pernambuco: problemas e perspectivas. Revta Econ 35(2):137-159. http://dx.doi.org/10.5380/re.v35i2.17207.

Silva Júnior S.S., Antonelli A.C., Soares G.W.N., Gomes I.M.M. \& Rocha Filho J.F. 2015. Determinação de cobre e outros minerais em caprinos e ovinos criados no sertão do vale do Rio São Francisco, Pernambuco. Pesq. Vet. Bras. 35(9):767-774. http://dx.doi.org/10.1590/S0100-736X2015000900001.

Silva T.R., Simões S.V.D., Miranda Neto E.G., Pereira Filho J.M., Assis A.C.O., Aguiar G.M.N., Lima F.A. \& Riet-Correa F. 2011. Efeitos da suplementação com fósforo em caprinos no semiárido do Nordeste Brasileiro. Arq. Bras. Med. Vet. Zootec. 63(5):1268-1271. http://dx.doi.org/10.1590/S010209352011000500035.

Smith B.P. 2006. Tratado de Medicina Interna de Grandes Animais. 3rd ed. Manole, São Paulo, p.700-731.

Smith M.C. \& Sherman D.M. 2009. Goat Medicine. 2ª ed. Lea and Febiger, Philadelphia, p.733-781. http://dx.doi.org/10.1002/9780813818825.

Stover S.M. 2006. Enfermidades dos ossos, das articulações e dos tecidos conjuntivos, p.1085-1148. In: Smith B.P. (Ed), Medicina Interna de Grandes

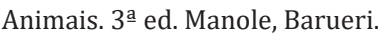

Ternouth J.C. \& Sevilla C.C. 1990. The effects of low levels of dietary phosphorus upon the dry matter intake and metabolism of lambs. Aust. J. Agricult. Res. 41(1):175-184. http://dx.doi.org/10.1071/AR9900175.

Thompson K. 2007. Bones and joints, p.82-88. In: Maxie M.G. (Ed), Jubb, Kennedy, and Palmer's Pathology of Domestic Animals. Vol.1. 5th ed. Elsevier, Philadelphia.

Thomas R.L., Sheard R.W. \& Moyer J.R. 1967. Comparasion of conventional and automated procedures for $\mathrm{N}, \mathrm{P}$ and $\mathrm{K}$ analysis of plant material using a single digestion. Agron. J. 59(3):240-243. http://dx.doi.org/10.2134/ agronj1967.00021962005900030010x

Tokarnia C.H., Peixoto P.V., Barbosa J.D., Brito M.F. \& Döbereiner J. 2010. Deficiências Minerais em Animais de Produção. Helianthus, Rio de Janeiro, p.16-57.

Tolosa E.M.C., Rodrigues C.J., Behmer O.A. \& Freitas Neto A. 2003. Manual de Técnicas para Histologia Normal e Patologia. 2a ed. Manole, Barueri, SP, p.47-81.

Underwood E.J. \& Suttle N.F. 1999. The Mineral Nutrition of Livestock. 3rd ed. CABI Publ., Waterford, p.122-167. http://dx.doi.org/10.1079/9780851991283.0000. 